modern molecular and cell biology are applied to a variety of traditional biological questions. The journal's subtitle. New's and Revien's in Molecular. Cellular and Derelopmental Biology, covers an enormous and growing field, but one which does not belong wholly inside any of the current Trends journals nor wholly inside any national scientific societies or international unions.

Does the existence and growth of work crossing the boundaries of the current mainstream disciplines warrant a distinct new review journal? Many articles in BioEssays would fit comfortably into Trends in Biochemistry. Trends in Genetics or Immunology Today. But on the evidence of the 12 issues available for review it appears that BioEssays, though broad in scope. is essentially filling the niche caused by the absence of a Trends in Cell Biologv, and by the enforced brevity of the mini-reviews in Cell.

Seen in those terms, there is no doubt

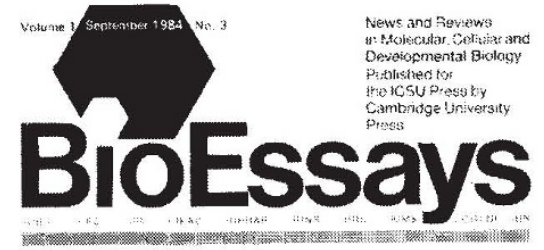

that the journal meets a genuine need and meets it well. The reviews are authoritative and clear, the occasional other articles are lively and the journal is generally wellwritten. It is not faultless, however. I find it rather dull to look at; even the best micrographs seem to lose impact on the fussy front cover, and some of the cover diagrams have been dismal. And it seems to me that the well-tried mixture of news and reviews is executed here without any striking originality. Still, this formula is well-tricd, precisely because it works. The short review gives enough scope for the author to convey results, opinions, arguments and sources, while not burdening the reader with too much detail. The features - articles on key laboratories, historical pieces, social comment, meeting reports - provide variety and frequently offer the seductive combination of enlightenment and gossip.

There is even a straightfaced regular column entitled "The Airport Professor" which purports, with great seriousness, to give advice on the best currency in which to buy air tickets, the best seats to ask for in a 747, warnings on dubious credit cards, advice on hire car rates, notes on road works near Singapore Airport, and so on. With a few pearls from "The Airport Professor" - did you know that departure tax at Mexico City Airport can be paid only in local currency? - no one need confess to a summer confined to the laboratory and the camp-site.

Robert Freedman is Senior Lecturer in the Biological Laboratory, University of Kent, Canterbury, Kent CT2 $7 N J, U K$.

\section{Looking at protocol}

\section{Kim Kaiser}

Gene Analysis Techniques. Editors Jack G. Chirikjian and Takis S. Papas. Elsevier, New York. 6/yr. North America $\$ 68$ (institutional), $\$ 34$ (individual); elsewhere $\$ 85$ (institutional), $\$ 51$ (individual).

NFw techniques arrive so thick and fast in molecular biology that I for one find it difficult to keep up with them, especially as they are often hidden away in the materials and methods sections of papers I have no other interest in. Moreover, as I suspect do most other people. I tend to resist changing from a familiar method until either a new technique has proved so popular with my colleagues that it is difficult to ignore it, or it has become codified in such experimental manuals as those published by Cold Spring Harbor Laboratory. Unfortunately (but inevitably) these manuals are to some extent out of date at the time of publication, yet they are still treated as bibles several years later.

In a way this is not a bad thing. That a procedure works is of prime importance and news of anything radically different quickly works its way through the grapevine. On the other hand, more-orless minor improvements that make a technique simpler, cheaper or more efficient are discovered from time to time, and it would be useful to have a forum whereby such improvements can be brought quickly to the attention of the laboratory worker. That such a need exists is exemplified by the success of newsletters such as Bethesda Research Laboratory's Focus. Focus articles are not refereed but feedback is accepted from readers.

Roughly half of the contributions to Gene Analysis Techniques, which still contains only three articles per issue halfway into its second year. of publication, are relatively simple modifications of or comments upon existing experimental protocols. Into this category fall papers such as that describing the successful substitu-

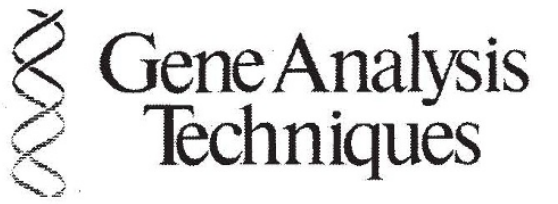

tion of cheap non-fat dried milk for the "Denhardt's ingredients" and sheared DNA of a hybridization mixture, one describing parameters that greatly enhance the efficiency of oligonucleotide extension during mutagenesis of DNA fragments in M13 vectors, and attempts to quantitate the efficiency with which genes introduced into mammalian cells are expressed. The rest of the papers concern newly developed techniques. Into this category fall both genuinely useful papers (many of which are of limited general interest. however), as well as some describing no doubt worthy techniques that are unlikely to be taken up by anybody but the inventor's colleagues since alternative and sometimes simpler methods are already in common use.

The production standard of the journal is good, papers appear at most four to five months after being received, and no doubt the cost of subscription would be saved if even a few of us substituted dried milk for BSA and salmon sperm DNA. However, no individual is likely to be interested in any but a proportion of the limited number of contributions each year. If the journal were available in our central university library I would make an effort to look at back issues once or twice a year as, I am sure, would many of my colleagues. It is too expensive, however, for our departmental library and not worth a personal subscription. Lastly, I would suggest to the editors that they provide a forum for discussion or updating of the published material.

Kim Kaiser is a Lecturer in the Department of Genetics, University of Glasgow, Church Street, Glasgow GII 5JS, UK.

\section{Ideas of oncology}

\section{John M. Goldman}

Critical Reviews in Oncology/Hematology. Editor Stephen Davis. CRC Press. 4/yr. North America \$104, elsewhere \$124.

Hematological Oncology. Editors J. W. Parker, R.J. Lukes, G.P. Canellos and J.M.A. Whitehouse. Wiley 4/yr. UK £62 (institutional), $£ 46.50$ (individual), $£ 31$ (student); North America $\$ 120$ (institutional), $\$ 90$ (individual), $\$ 60$ (student).

THE AIM of Critical Reviews in Oncology/ Hematology is "to compile manuscripts which summarize evolving concepts within the broad disciplines of oncology and hematology .... [The] subject matter will be discussed in a timely, critical and analytical manner".

In practice the journal follows the standard CRC Critical Reviews format. The editor invites two or three reviews on widely differing topics for each issue, and then submits the finished manuscript to an independent referee whose job is to correct errors and draw attention to omissions. The result in most cases is an excellent and comprehensive review, such as "Staging for conservative management of Hodgkin's disease", "Monoclonal antibodies in cancer", "The fibrinolytic system in man" or "Internal mammary scintigraphy", written by undoubted experts in the field. Each review runs to about 25 or 30 pages. The number of references varies from about 100 to more than 500 .

I can see just two drawbacks in this approach. First, the very wide range of 